\title{
Comparison of phenolic content and antioxidant activity of two common fruits of Bangladesh in solvents of varying polarities
}

\author{
Ghosh, R., Barua, P., Sikder, O., Saha, S., Mojumder, S. and *Sikdar, D. \\ Department of Biochemistry and Molecular Biology, University of Chittagong, Chittagong-4331, \\ Bangladesh
}

\section{Article history:}

Received: 6 April 2021

Received in revised form: 16

May 2021

Accepted: 17 June 2021

Available Online: 12

December 2021

Keywords:

Phenolic content, Antioxidant activity, Solvent effect,

Phyllunthus emblica,

Elaeocarpus floribundus.

DOI:

https://doi.org/10.26656/fr.2017.5(6).253

\begin{abstract}
Phenolic content and antioxidant activity of two common fruits of Bangladesh, namely Phyllunthus emblica and Elaeocarpus floribundus, were measured in water, methanol, ethanol, acetone and hexane extracts. Several in vitro models including phosphomolybdenum assay, DPPH free radical scavenging assay, FRAP assay and reducing power assay were used to assess the antioxidant activity of these extracts in comparison with reference antioxidants. Between the two fruits, P. emblica showed higher phenolic content and antioxidant activity in all the solvents used. In the DPPH scavenging assay, the activity of $P$. emblica extracts was close to reference antioxidants, ascorbic acid and BHT. Besides, considering the solvents used, extracts of both fruits had the highest phenolic and antioxidant activity in polar solvents. The correlation coefficient between total phenolics and antioxidant activities was found statistically significant. These findings suggest that $P$. emblica could be an excellent antioxidant resource for industries like food, pharmaceutical, and cosmetics.
\end{abstract}

\section{Introduction}

In a biological system, reactive oxygen species and reactive nitrogen species such as superoxide, hydroxyl, and nitric oxide radicals can damage DNA and lead to the oxidation of lipid and protein in cells, causing some chronic and degenerative diseases (Nunes et al., 2012; Aktumsek et al., 2013; Xu et al., 2017). Recent studies indicate that because of the presence of antioxidants especially, polyphenols and carotenoids, frequent consumption of fruits and vegetables is associated with a lower risk of inflammation, stroke, cancer, diabetes and neurodegenerative diseases (Garsia-Salas et al., 2010; Khoddami et al., 2013; Zhang et al., 2015). Antioxidant molecules block both the initiation and propagation of oxidizing chain reactions, thereby impeding or slowing the oxidation process (Lobo et al., 2010; Nunes et al., 2012).

Fruits of P. emblica and E. floribundus, locally known as amloki and jolpai, respectively, are two wellconsumed fruits of Bangladesh. The plant P. emblica, belonging to the family Euphorbiaceae, is indigenous to the tropical region of Southeast Asia. It is generally found throughout the forests of Chittagong, Chittagong Hill Tracts, Cox's Bazar, Dinajpur, Tangail, Sylhet, and villages of Bangladesh (Uddin et al., 2016). It is highly nutritious and rich in vitamin $\mathrm{C}$, minerals and amino acids. All parts of this plant have medicinal properties, especially the fruits that are used in Ayurveda as a potent Rosayan (rejuvenator). The plant is reported to have various pharmaceutical potentials including antiinflammatory, analgesic and antipyretic, antioxidant, antimicrobial, hepatoprotective, antitumor, immunomodulatory, anti-atherogenic, antiulcerogenic, and adaptogenic activities (Khopde et al., 2001; Krishnaveni and Mirunalini, 2010; Gaire and Subedi, 2014; Uddin et al., 2016; Chaphalkar et al., 2017).

On the other hand, plant E. floribundus belongs to the family Elaeocarpaceae and is found in the South and East Asian region including Bangladesh (Zaman, 2016; Swargiary et al., 2017). The fruits of this plant are traditionally used to prepare pickles (Zaman, 2016) and the seeds are used to prepare oil in Myanmar (Shin et al., 2018). The plant has various biological activities like antioxidant, antibacterial, cytotoxic, anti-ageing and anticancer (Utami et al., 2013; Sircar and Mandal, 2017; Deivasigamani and Devi, 2018).

The phenolic composition of plants depends on many factors such as genetic, seasonal, agronomic, maturation stage and growing conditions like temperature and rainfall (Hilton and Palmer-Jones, 1973; 
Wang and Zheng, 2001; Zietz et al., 2010). The solubility of phenolic compounds in the extraction medium, however, affect their extraction from plant tissues (Park et al., 2014).

There are many reports on the phenolic contents and antioxidant activities of $P$. emblica fruits extracted with different solvents and grown in South and East Asian regions especially in India, China, Indonesia, Thailand (Khopde et al., 2001; Charoenteeraboon et al., 2010; Li et al., 2015; Fitriansyah et al., 2018; Li et al., 2019). However, there is a scarcity of studies, if any, showing the effect of solvent types, covering apolar to the polar range, on the phenolic content and antioxidant activities of this fruit. Although the phenolic contents and antioxidant activities of $P$. emblica fruit grown in Bangladesh has been reported (Rahman et al., 2016; Mondal et al., 2017) but the effect of the solvents on the extraction of phenolic contents and antioxidant activities are not studied. Moreover, detail antioxidant activities of this fruit by different in vitro methods and their comparison with reference antioxidants were not studied yet.

On the other hand, to the best of our knowledge, limited research has been done on extraction, quantification and comparison of phenolic compounds of E. floribundus fruit with different solvents. Sircar and Mandal (2017) reported the phenolic content and DPPH free radical scavenging activity of this fruit in ethanol and aqueous extract. However, the report on the phenolic compositions and antioxidant activities of this fruit grown in Bangladesh is seldom, if any.

In this study, the phenolic contents and antioxidative capacities of $P$. emblica and E. floribundus fruits grown in Bangladesh have been investigated and compared. Moreover, the effect of solvents on the extraction of phenolic compounds with the antioxidant potential of these two fruits has also been studied in order to find the appropriate solvent for extraction.

\section{Materials and methods}

\subsection{Chemicals and reagents}

Folin-ciocalteu reagent, sodium carbonate, sodium nitrate, ferric chloride, sodium acetate were purchased from BDH Chemicals Ltd. Poole, England. Ethanol, sulphuric acid, hydrochloric acid, glacial acetic acid and disodium hydrogen phosphate were purchased from Merck, Darmstadt, Germany. Aluminium chloride, sodium hydroxide and sodium dihydrogen phosphate were purchased from Merck, Mumbai, India. Gallic acid, 2,4,6-Tris (1-pyridyl)-5-triazine (TPTZ), 1,1-diphenyl-2picrylhydrazyl (DPPH), butylated hydroxytoluene (BHT) and potassium ferricyanide were purchased from Sigma-
Aldrich, St. Louis, USA. Ammonium molybdate and trichloroacetic acid (TCA) were purchased from Loba chemie, Mumbai, India. All chemicals and reagents used in this study were of analytical grade.

\subsection{Plant materials}

Fruits of Phyllanthus emblica L. and Elaeocarpus floribundus Blume (Figure 1) were collected from Chittagong, Bangladesh in October to November, 2018 and were properly authenticated by Dr. Sarder Nasir Uddin, Principal Scientific Officer, Bangladesh National Herbarium, Dhaka, Bangladesh where voucher specimens with accession numbers DACB 51334 and DACB 51335, respectively have been deposited. All the selected fruits were identical in size, shape, colour, ripening stages and were also of eating quality.

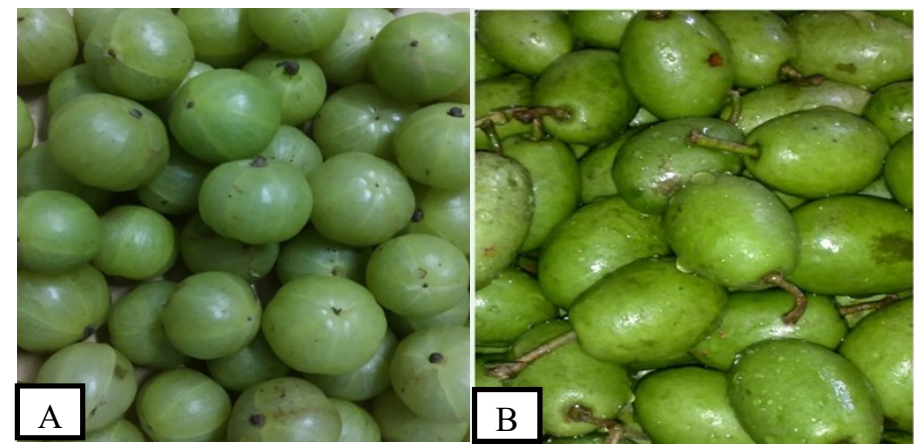

Figure 1. The studied fruits. A $-P$. emblica, B $-E$. floribundus.

\subsection{Sample preparation}

The freshly collected matured fruits were initially washed thoroughly with tap water until the attached dust particles, unicellular algae etc. were removed. Finally, they were washed with distilled water. The fruits were chopped and seeds were removed. The resulting fruit parts were dried in Economy Incubator (Size 2) at $50^{\circ} \mathrm{C}$ for $10 \mathrm{hrs}$. The dried fruits were grounded into powder with a grinder. The powders were stored separately in air -tight containers and kept in a refrigerator at $-80^{\circ} \mathrm{C}$.

For extraction of phenolic compounds, $10 \mathrm{~g}$ powder of each fruit was placed separately in a conical flask and soaked in $100 \mathrm{~mL}$ of a different solvent system. Each container was sealed and shaken intermittently for 4 days. On the $5^{\text {th }}$ day, fruit extracts were filtered through $0.45 \mu \mathrm{m}$ filter paper and the filtrate was stored in a fresh conical flask at $4{ }^{\circ} \mathrm{C}$. To the residue, $100 \mathrm{~mL}$ solvent was further added and left for 3 days with regular shaking. On the $7^{\text {th }}$ day, the filtration process was repeated as was done previously and the resulting extract was mixed with those previously stored. Then the preparations were evaporated in a rotary evaporator at $50^{\circ} \mathrm{C}$ to get the solid crude extract. The extraction yield was measured and expressed as a percentage. The obtained crude extract 
was kept in a refrigerator at $4^{\circ} \mathrm{C}$ until further analysis. Five different pure solvent systems including water, methanol, ethanol, acetone and n-hexane (Gorinstein et al., 2010; Lee et al., 2015) with the relative polarity of 1 , $0.762,0.654,0.355$ and 0.009 , respectively were used for extraction. To avoid microbial contamination while extracting with water, aseptic conditions were maintained (Aiyegoro and Okoh, 2009). Dimethyl sulfoxide (DMSO) was used to dissolve all extracts for subsequent analysis.

\subsection{Determination of total polyphenol content}

Total polyphenol content was estimated following the method of Ough and Amerine (1988). A $20 \mu \mathrm{L}$ of sample extract was diluted with $2.58 \mathrm{~mL}$ distilled water. Then $100 \mu \mathrm{L}$ of Folin-Ciocalteu reagent was added. After $1 \mathrm{~min}, 300 \mu \mathrm{L}$ of $20 \%$ sodium carbonate solution was added and mixed. The mixture was then incubated for 2 hours at room temperature. The absorbance of the resulting blue colour supernatant was measured at 765 nm (UV-1601 Shimadzu, Kyoto, Japan). All samples were analyzed in triplicates. A standard calibration curve of gallic acid $\left(0.002-0.01 \mathrm{mg} / \mathrm{mL}, \mathrm{r}^{2}=0.997\right)$ was plotted. The total phenolic content was expressed as $\mathrm{mg}$ gallic acid equivalent (GAE)/g dry fruits weight (DW).

\subsection{Determination of total flavonoid content}

Total flavonoid contents of the fruit extracts were determined following the method of Zhishen et al. (1999). An aliquot $(0.2 \mathrm{~mL})$ of fruit extract was mixed with $4.8 \mathrm{~mL}$ of distilled water and $0.3 \mathrm{~mL}$ of $(5 \% \mathrm{w} / \mathrm{v})$ $\mathrm{NaNO}_{2}$ was added. After $5 \mathrm{~min}, 0.3 \mathrm{~mL}$ of $(10 \% \mathrm{w} / \mathrm{v})$ $\mathrm{AlCl}_{3}$ was added and after another minute, $2 \mathrm{~mL}$ of $\mathrm{NaOH}(1 \mathrm{M})$ was added. To make the final volume 10 $\mathrm{mL}, 2.4 \mathrm{~mL}$ of distilled water was added immediately. The absorbance of the vigorously mixed resulting solution was read at $510 \mathrm{~nm}$ (UV-1601 Shimadzu, Kyoto, Japan). A calibration curve was prepared using a standard solution of quercetin $\left(0.002-0.01 \mathrm{mg} / \mathrm{mL}, \mathrm{r}^{2}=\right.$ 0.992). The results were presented as $\mathrm{mg}$ quercetin equivalents $(\mathrm{QE}) / \mathrm{g}$ DW.

\subsection{Determination of antioxidant activities}

\subsubsection{DPPH free radical-scavenging activity (FRSA)} assay

The reaction mixture (total volume, $3 \mathrm{~mL}$ ), consisting of $0.5 \mathrm{~mL}$ of $0.5 \mathrm{M}$ acetic acid buffer solution (pH 5.5), $1 \mathrm{~mL}$ of $0.2 \mathrm{mM}$ DPPH in ethanol, and $1.5 \mathrm{~mL}$ of $50 \%(\mathrm{v} / \mathrm{v})$ ethanol aqueous solution with different concentrations of extracts, was shaken vigorously (Hossain et al., 2008). After incubation at room temperature $\left(25^{\circ} \mathrm{C}\right)$ for 30 mins, the amount of DPPH remaining was determined by measuring absorbance at $517 \mathrm{~nm}$. Ascorbic acid and BHT were used as a reference. The percentage of inhibition of DPPH radicals was calculated using the following formula:

$$
\% \text { inhibition }=\frac{(\text { Acontrol }- \text { Asample }) \times 100}{\text { Acontrol }}
$$

Where Acontrol is the absorbance of DPPH solution without extract.

\subsubsection{Evaluation of total antioxidant capacity}

The total antioxidant capacities of the extracts were evaluated by phosphomolybdenum method according to Prieto et al. (1999). An aliquot of $400 \mu \mathrm{L}$ of sample solution was combined in a screw cap tube with $4 \mathrm{~mL}$ of reagent solution $(0.6 \mathrm{M}$ sulfuric acid, $28 \mathrm{mM}$ sodium phosphate, and $4 \mathrm{mM}$ ammonium molybdate). The tubes were capped and incubated in a thermal block at $95^{\circ} \mathrm{C}$ for 90 mins and cooled to room temperature. The absorbance was measured at $695 \mathrm{~nm}$ against a blank. The typical blank was prepared as a sample except solvent DMSO was added instead of sample and was incubated under the same conditions as that of a sample. The antioxidant capacity of the sample was expressed as equivalents of ascorbic acid (AAE), utilizing a calibration curve of ascorbic acid in the concentration range from $0.02 \mathrm{mg} / \mathrm{mL}$ to $0.32 \mathrm{mg} / \mathrm{mL}\left(\mathrm{r}^{2}=0.994\right)$.

\subsubsection{Determination of ferric reducing antioxidant power (FRAP)}

The FRAP assay was determined by the method described by Benzie and Strain (1996) with slight modifications. The FRAP reagent was prepared freshly by mixing $300 \mathrm{mM}$ acetate buffer $(\mathrm{pH} 3.6), 10 \mathrm{mM}$ TPTZ and $20 \mathrm{mM}$ ferric chloride in a ratio of 10:1:1 (v/ $\mathrm{v} / \mathrm{v})$. FRAP reagent was pre-warmed at $37^{\circ} \mathrm{C}$ for $30 \mathrm{mins}$ and different volumes $(10,20,40,80,160,240$ and 320 $\mu \mathrm{L})$ of properly diluted fruit extract was mixed with 3 $\mathrm{mL}$ of FRAP reagent. The reaction mixture was then incubated in dark for 30 mins. and the absorbance was determined at $593 \mathrm{~nm}$. The antioxidant potential of the fruit extract was determined based on a calibration curve plotted using $\mathrm{FeSO}_{4} .7 \mathrm{H}_{2} \mathrm{O}\left(4.29-85.8 \mu \mathrm{M}, \mathrm{r}^{2}=0.999\right)$. Ascorbic acid and BHT were used as a reference.

\subsubsection{Reducing power assay}

The ferric reducing power was assayed with slight modifications of the method described by Oyaizu (1986). Various concentrations of the extracts $(40 \mu \mathrm{L})$ were mixed with $2.46 \mathrm{~mL}$ of $0.2 \mathrm{M}$ phosphate buffer (pH 6.6) and $2.5 \mathrm{~mL}$ of $1 \%$ potassium ferricyanide. The mixture was incubated at $50^{\circ} \mathrm{C}$ for 20 mins. After incubation, followed by cooling for a few minutes, $2.5 \mathrm{~mL}$ of $10 \%$ trichloroacetic acid was added. The resulting mixture was centrifuged at $650 \mathrm{~g}$ for 10 mins. A $2.5 \mathrm{~mL}$ of the 
supernatant was mixed with $2.5 \mathrm{~mL}$ distilled water and $0.5 \mathrm{~mL}$ of $0.1 \%$ ferric chloride. The absorbance of the mixture was measured at $700 \mathrm{~nm}$. Ascorbic acid was used as a reference.

\subsection{Statistical analysis}

The SPSS package, version 19.0 (SPSS Inc., Chicago, IL, USA) was used to perform the statistical analysis. Analysis of variance (ANOVA) and Duncan's multiple range method was used to compare the mean values. Data were expressed as mean \pm standard deviation of triplicate measurements. Differences were considered significant at $\mathrm{P}<0.05$. The $\mathrm{IC}_{50}$ values were calculated by linear regression analysis. Pearson's correlation coefficient was used to do determine correlations.

\section{Results and discussion}

In this study, the phenolic contents and antioxidant activities of two commonly consumed fruits of Bangladesh named amloki and jolpai were first compared. To the author's knowledge, there is a single previous study investigating the efficiency of solvents of different polarities (n-hexane, ethyl acetate and hexane) on the extraction of phenolic contents of $P$. emblica grown in Indonesia (Fitriansyah et al., 2018). Furthermore, study on phytochemical contents and antioxidant activity of $E$. floribindus fruit is rare. In this study, we used five solvents of differing polarities in the following order: water, methanol, ethanol, acetone, hexane.

\subsection{Extraction yield and antioxidant components}

The influence of solvents on the extraction yield of both fruits is shown in Table 1. Among the different solvent extracts, the water extracts had the highest yield for both fruits, followed by methanol, ethanol, acetone, then n-hexane extracts. The aqueous extracts of plants are commonly found to show higher yields than other solvent extracts (Kong et al., 2012). Of the two fruits, the extraction yield of $P$. emblica was higher than that of the E. floribundus for all solvents.

Table 1. Percent yield of crude extract from two fruits in different solvent

\begin{tabular}{ccc}
\hline \multirow{2}{*}{ Extraction Solvent } & \multicolumn{2}{c}{ Yield (\%) } \\
\cline { 2 - 3 } & P. emblica & E. floribundus \\
\hline Water & 45.7 & 23.9 \\
Methanol & 26 & 7.3 \\
Ethanol & 23.1 & 6.7 \\
Acetone & 6.9 & 1.8 \\
n-Hexane & 0.8 & 0.7 \\
\hline
\end{tabular}

The total phenolic and flavonoid contents in the $P$. emblica and E. floribundus extracts are summarized in Table 2. It was found that the phenolics and flavonoids of P. emblica and E. floribundus were higher in a polar solvent such as water, methanol, and ethanol, implying that most polyphenols in these fruits are polar. A similar effect of the polarity of solvent on phenolic and flavonoid contents of plant materials were reported by Kong et al. (2012), Lee et al. (2015), and Belyagoubi et al. (2016), as well. Similar to the extraction yield, $P$. emblica had higher phenolic (0.28-103.95 mg GAE/g DW) and flavonoid contents (0.56-30.88 mg QE/g DW) than the phenolic (0.04-3.62 $\mathrm{mg}$ GAE/g DW) and flavonoid (0.16-1.42 mg QE/g DW) contents of $E$. floribundus fruit in all solvents. It is difficult to compare the phenolic and flavonoid content of a particular fruit determined by other studies as the method of extraction, assay and unit of expression varies. However, similar phenolic content (81.5 to $120.9 \mathrm{mg}(\mathrm{GAE}) / \mathrm{g} \mathrm{DW}$ ) and flavonoid content (20.3 to $38.7 \mathrm{mg}(\mathrm{QE}) / \mathrm{g} \mathrm{DW}$ ) was reported by Liu et al. (2008) in the methanolic extract of the fruit emblica from six regions of China. Microwave extraction of $P$. emblica fruits, collected from Fujian province of China, with $66 \%$ ethanol produced $133.58 \pm 15.61 \mathrm{mg}$ GAE/g DW phenolics (Li et al., 2019). The Folin-Ciocalteu reagent method may overestimate TPC, because reducing agents, such as ascorbic acid, may interfere with the results. However, different phenolic compounds respond in the Folin-Ciocalteu method (Ikram et al. 2009). Correlation analysis was

Table 2. Phenolic and flavonoid content of two fruits extracted with different solvent

\begin{tabular}{lcccc}
\hline \multirow{2}{*}{ Solvent } & \multicolumn{2}{c}{ P. emblica } & \multicolumn{2}{c}{ E. floribundus } \\
\cline { 2 - 5 } & $\begin{array}{c}\text { Total phenolics } \\
(\mathrm{mg} \mathrm{GAE} / \mathrm{g} \mathrm{dw})\end{array}$ & $\begin{array}{c}\text { Total Flavonoids } \\
(\mathrm{mg} \mathrm{QE} / \mathrm{g} \mathrm{dw})\end{array}$ & $\begin{array}{c}\text { Total phenolics } \\
(\mathrm{mg} \mathrm{GAE} / \mathrm{g} \mathrm{dw})\end{array}$ & $\begin{array}{c}\text { Total Flavonoids } \\
(\mathrm{mg} Q \mathrm{~g} / \mathrm{g} \mathrm{dw})\end{array}$ \\
\hline Water & $98.25 \pm 0.00^{\mathrm{d}, \mathrm{B}}$ & $30.88 \pm 0.32^{\mathrm{e}, \mathrm{B}}$ & $3.62 \pm 0.18^{\mathrm{e}, \mathrm{A}}$ & $1.42 \pm 0.12^{\mathrm{e}, \mathrm{A}}$ \\
Methanol & $84.93 \pm 0.75^{\mathrm{c}, \mathrm{B}}$ & $18.21 \pm 0.46^{\mathrm{c}, \mathrm{B}}$ & $0.91 \pm 0.00^{\mathrm{d}, \mathrm{A}}$ & $0.96 \pm 0.02^{\mathrm{d}, \mathrm{A}}$ \\
Ethanol & $103.95 \pm 0.00^{\mathrm{e}, \mathrm{B}}$ & $19.4 \pm 0.24^{\mathrm{d}, \mathrm{B}}$ & $0.67 \pm 0.07^{\mathrm{c}, \mathrm{A}}$ & $0.79 \pm 0.02^{\mathrm{c}, \mathrm{A}}$ \\
Acetone & $14.83 \pm 0.00^{\mathrm{b}, \mathrm{B}}$ & $5.57 \pm 0.03^{\mathrm{b}, \mathrm{B}}$ & $0.12 \pm 0.00^{\mathrm{b}, \mathrm{A}}$ & $0.30 \pm 0.01^{\mathrm{b}, \mathrm{A}}$ \\
n-Hexane & $0.28 \pm 0.0023^{\mathrm{a}, \mathrm{B}}$ & $0.56 \pm 0.01^{\mathrm{a}, \mathrm{B}}$ & $0.04 \pm 0.00^{\mathrm{a}, \mathrm{A}}$ & $0.16 \pm 0.00^{\mathrm{a}, \mathrm{A}}$ \\
\hline
\end{tabular}

Values are presented as mean $\pm \mathrm{SD}, \mathrm{n}=3$. Values with different lowercase superscript are significantly different at $\mathrm{p}<0.05$ among the extraction solvents while values with different uppercase superscript are significantly different at $\mathrm{p}<0.05$ between fruits. 
performed between the phenolic contents and flavonoid contents of both fruits. The correlations between TP and TF assays were 0.919 for $P$. emblica and 0.897 for $E$. floribundus, respectively which were highly significant at the 0.01 level, indicating that the flavonoids are an important phenolic group that contributes to the antioxidant capacity of P. emblica and E. floribundus.

\subsection{Antioxidant activities}

Due to the presence of a variety of antioxidant compounds with different polarities in fruits the antioxidant capacity of fruits differs with the solvent extraction methods. Moreover, antioxidants may respond to different radical or oxidant sources in a different manner. Thus, no single assay can accurately reflect all of the radical sources and antioxidants present in a mixed or complex system as multiple reaction characteristics, mechanisms, and phase localizations are usually involved (Park et al., 2014). Many different methods are used to assay the antioxidant activity of plant extracts (Alam et al., 2013; Pisoschi et al., 2016; Zengin et al., 2018). In this study, we applied four different antioxidant assay methods that would provide a better insight into the true antioxidant potential of the extracts.

\subsubsection{2,2-Diphenyl-1-picryl hydrazyl radical-scavenging activity}

(DPPH)

The assay of scavenging of stable organic radical DPPH has been widely used in antioxidant capacity studies of plant extracts or antioxidant compounds. The antioxidant activity of plant extracts is thought to be due to its ability to transfer hydrogen or electron to $\mathrm{DPPH}$, thus neutralizing its free radical character. In this assay, the purple radical (picrylhydrazyl) is reduced by antioxidant compounds to the corresponding pale yellow hydrazine (picrylhydrazine), in a concentrationdependent manner. The discolouration indicates the FRSA of the tested sample (Rahman et al., 2015).

The abilities of the studied fruit extracts to scavenge DPPH were assessed based on their $\mathrm{IC}_{50}$. The $\mathrm{IC}_{50}$ of an antioxidant is defined as the amount of the antioxidant needed to decrease the radical concentration by $50 \%$ and its values are inversely related to the antioxidant capacities. Table 3 shows the FRSA of the extracts of $P$. emblica and E. floribundus fruits. For both fruits, the antioxidant strength varied with the polarity of the extraction solvent. Similar to its highest total phenolic content in ethanolic extract, the same extract of $P$. emblica showed the highest FRSA, closer to the reference antioxidant BHT $(0.10 \pm 0.001 \mathrm{mg} / \mathrm{mL})$ but weaker than ascorbic acid $(0.07 \pm 0.002 \mathrm{mg} / \mathrm{mL})$, implying its potencies. The methanol and acetone extracts of $P$. emblica also showed strong FRSA which were close to BHT. Water extract showed relatively poor scavenging activity compared to BHT and n-hexane extract showed the least activity. A similar effect of solvents on the DPPH radical scavenging activity was observed by Do et al. (2014) while studying the solvent effect on the antioxidant activity of $L$. aromatica. In most instances, the hexane extracts were the least reactive in scavenging the DPPH radicals (Kong et al., 2012). A high total phenolic content is not always associated with a high FRSA. As reported by Bhebhe et al. (2016), ethanol (50\%) extracts from $S$. jambolonum had the highest FRSA, yet they recorded lower TPC than $50 \%$ acetone and hot water. In this study, although water extract had higher phenolic content than methanol and acetone extract but the former showed lower FRSA.

The scavenging activity of E. floribundus varied clearly with the polarity of the solvent, i.e. strongest scavenging activity in water but the weakest in acetone, in accordance with its phenolic and flavonoid contents in different solvents. Earlier reports indicated that the FRSA of phenolic extracts varies from plant to plant such that only a suitable solvent for a particular plant may extract phenolics with the highest activity. A solvent may be efficient on one plant and less efficient on another. The phenomena may be explained by the fact that the recovery of antioxidant compounds such as polyphenols from plant materials is influenced by the

Table 3. Antioxidant activities of the fruit extracts in different solvent

\begin{tabular}{lcccccc}
\hline & \multicolumn{3}{c}{ P. emblica } & & \multicolumn{2}{c}{ E. floribundus } \\
\cline { 2 - 7 } Solvent & $\mathrm{DPPH} \cdot$ scavenging & Total antioxidant & FRAP & DPPH· scavenging & Total antioxidant & FRAP \\
\cline { 2 - 7 } & $\mathrm{IC}_{50}(\mathrm{mg} / \mathrm{mL})$ & $(\mathrm{mg} \mathrm{AAE} / \mathrm{g} \mathrm{dw})$ & $\left(\mathrm{mmol} \mathrm{Fe}^{2+} / \mathrm{g} \mathrm{dw}\right)$ & $\mathrm{IC} 50(\mathrm{mg} / \mathrm{mL})$ & $(\mathrm{mg} \mathrm{AAE} / \mathrm{g} \mathrm{dw})$ & $(\mathrm{mmol} \mathrm{Fe} / \mathrm{g} \mathrm{dw})$ \\
\hline Water & $0.15 \pm 0.002^{\mathrm{c}, \mathrm{A}}$ & $158.81 \pm 0.99^{\mathrm{e}, \mathrm{B}}$ & $1362.15 \pm 33.49^{\mathrm{e}, \mathrm{B}}$ & $3.03 \pm 0.04^{\mathrm{a}, \mathrm{B}}$ & $53.38 \pm 0.28^{\mathrm{d}, \mathrm{A}}$ & $29.50 \pm 0.58^{\mathrm{d}, \mathrm{A}}$ \\
Methanol & $0.11 \pm 0.001^{\mathrm{b}, \mathrm{A}}$ & $96.18 \pm 0.72^{\mathrm{d}, \mathrm{B}}$ & $933.76 \pm 7.35^{\mathrm{d}, \mathrm{B}}$ & $5.79 \pm 0.03^{\mathrm{c}, \mathrm{B}}$ & $10.65 \pm 0.64^{\mathrm{c}, \mathrm{A}}$ & $5.67 \pm 0.37^{\mathrm{b}, \mathrm{A}}$ \\
Ethanol & $0.09 \pm 0.001^{\mathrm{a}, \mathrm{A}}$ & $82.54 \pm 1.13^{\mathrm{c}, \mathrm{B}}$ & $730.86 \pm 17.63^{\mathrm{c}, \mathrm{B}}$ & $4.87 \pm 0.11^{\mathrm{b}, \mathrm{B}}$ & $10.54 \pm 0.07^{\mathrm{c}, \mathrm{A}}$ & $6.20 \pm 0.24^{\mathrm{c}, \mathrm{A}}$ \\
Acetone & $0.11 \pm 0.000^{\mathrm{b}, \mathrm{A}}$ & $22.76 \pm 0.86^{\mathrm{b}, \mathrm{B}}$ & $236.33 \pm 6.90^{\mathrm{b}, \mathrm{B}}$ & $12.32 \pm 0.25^{\mathrm{d}, \mathrm{B}}$ & $2.66 \pm 0.09^{\mathrm{b}, \mathrm{A}}$ & $0.85 \pm 0.06^{\mathrm{a}, \mathrm{A}}$ \\
n-Hexane & $1.02 \pm 0.006^{\mathrm{d}}$ & $1.48 \pm 0.02^{\mathrm{a}, \mathrm{B}}$ & $8.66 \pm 0.29^{\mathrm{a}}$ & $\mathrm{NA}$ & $1.12 \pm 0.04^{\mathrm{a}, \mathrm{A}}$ & $\mathrm{NA}$ \\
\hline
\end{tabular}

Values are presented as mean $\pm \mathrm{SD}, \mathrm{n}=3$. Values with different lowercase superscript are significantly different at $\mathrm{p}<0.05$ among the extraction solvents while values with different uppercase superscript are significantly different at $\mathrm{p}<0.05$ between fruits. 
solubility of the phenolic compounds in the solvent used for the extraction. Moreover, the polarity of the solvent will play an important role in increasing the solubility of phenolic compounds (Bhebhe et al., 2016). All extracts of E. floribundus showed lower DPPH radical scavenging activities than $P$. emblica and standard antioxidants. This can be attributed mainly due to the lower phenolic content of E. floribundus than P. emblica. However, the hexane extract of E. floribundus did not reach the $50 \%$ inhibition of the DPPH radicals at the concentration tested.

\subsubsection{Total antioxidant capacity}

The total antioxidant capacity was determined by phosphomolybdenum method based on reduction of Mo (VI) to $\mathrm{Mo}(\mathrm{V})$ by antioxidant substance and subsequent formation of a green phosphate $\mathrm{Mo}(\mathrm{V})$ compounds at acidic $\mathrm{pH}$ with an absorbance at $695 \mathrm{~nm}$ (Aktumsek et al., 2013). The water extracts of $P$. emblica and $E$. floribundus fruits had the highest antioxidant capacity $(158.81 \pm 0.99$ and $53.3 \pm 0.28 \mathrm{mg} \mathrm{AAE} / \mathrm{g} \mathrm{dw}$, respectively), whereas hexane extracts had the lowest (1.48 \pm 0.02 and $1.12 \pm 0.04 \mathrm{mg} \mathrm{AAE} / \mathrm{g} \mathrm{DW}$, respectively). Besides, P. emblica showed a higher total antioxidant capacity than E. floribundus for all solvent extracts (Table 3).

\subsubsection{Ferric reducing antioxidant activity}

The assay is based on the ability of antioxidant compounds to a reducing complex, Fe(III)-TPTZ to Fe (II)-TPTZ. This reduction is associated with the colour change from light blue to dark blue with an absorbance maximum at $593 \mathrm{~nm}$ (Ezzati Nazhad Dolatabadi et al., 2014). The ferric reducing antioxidant activities of the different extracts of $P$. emblica and E. floribundus fruits are presented in Table 3 . The ferric reducing power of $P$. emblica fruit was higher than E. floribundus for all solvents. Again, water extract and hexane extract of both $P$. emblica and E. floribundus fruits showed the highest (1362.15 \pm 33.49 and $29.50 \pm 0.58 \mathrm{mmol} \mathrm{Fe}^{2+} / \mathrm{g} \mathrm{DW}$, respectively) and lowest reducing activity $(8.66 \pm 0.29$

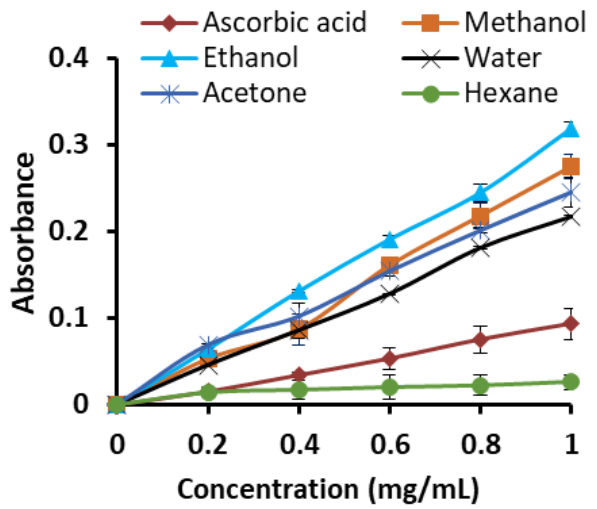

mmol $\mathrm{Fe}^{2+} / \mathrm{g}$ DW and undetectable, respectively), respectively. The ferric reducing antioxidant power of ascorbic acid and BHT were $413.96 \pm 12.35 \mathrm{mmol} / \mathrm{g}$ and $157.15 \pm 6.77 \mathrm{mmol} / \mathrm{g}$, respectively. The highest and lowest FRAP activity was also reported in the water and hexane extract, respectively of black mustard seeds (Lee et al., 2015). Moreover, the FRAP and TAC values of both fruits showed a similar trend. The FRAP activity of hexane extract of E. floribundus could not be measured due to its low activity.

\subsubsection{Reducing power activity (Iron(III) to iron(II) reduction)}

Literature reports suggest that the reducing properties are generally associated with the presence of reductones. The reductones have been shown to exert antioxidant activity by breaking the free radical chain by donating a hydrogen atom. In the ferric reducing assay, the presence of antioxidants causes the conversion of the $\mathrm{Fe}^{3+} /$ ferricyanide complex to the ferrous form which can be monitored by measuring the formation of Perl's Prussian blue at $700 \mathrm{~nm}$ (Alam et al., 2016). In this study, the ferric reducing activity of different extracts of two fruits was evaluated. Figure 2 shows the dosedependency of ferric reducing power of different solvent extract of both fruits and ascorbic acid. The reducing power of all extracts increased with increased concentration. Dose dependency was also shown by ascorbic acid. Ethanol and water extracts showed the highest reducing activity for $P$. emblica and $E$. floribundus fruits, respectively, in accordance with their highest phenolic content whereas, for both fruits, hexane showed the lowest activity similar to other antioxidant assays. All the solvent extracts of $P$. emblica showed higher ferric reducing activity than ascorbic acid except hexane. The ferric reducing activity of hexane extract of E. floribundus was not found at the concentration tested due to its poor activity.

\subsection{Correlation analyses}

Pearson correlation analyses were done to estimate

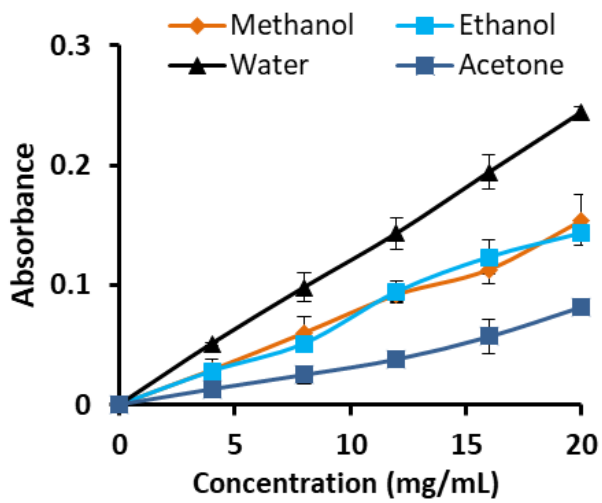

Figure 2. Dose dependency of P. emblica (A) and E. floribundus (B) fruit extracts in different solvent and comparison with reference antioxidant ascorbic acid. 
Table 4. Correlation coefficient between total phenolic content and antioxidant activity

\begin{tabular}{lcccc}
\hline & \multicolumn{3}{c}{ Correlation coefficient (r) } \\
\cline { 2 - 4 } & \multicolumn{2}{c}{ P. emblica } & \multicolumn{2}{c}{ E. floribundus } \\
\cline { 2 - 4 } & Total phenolics & Flavonoids & Total phenolics & Flavonoid \\
\hline Free radical scavenging activity $\left(\mathrm{IC}_{50}\right)$ & $-0.681^{\mathrm{b}}$ & $-0.642^{\mathrm{b}}$ & -0.724 & $-0.918^{\mathrm{a}}$ \\
Total antioxidant capacity & $0.882^{\mathrm{a}}$ & $0.992^{\mathrm{a}}$ & $0.997^{\mathrm{a}}$ & $0.874^{\mathrm{a}}$ \\
Ferric reducing antioxidant power & $0.891^{\mathrm{a}}$ & $0.986^{\mathrm{a}}$ & $0.997^{\mathrm{a}}$ & $0.889^{\mathrm{a}}$ \\
\hline
\end{tabular}

${ }^{\mathrm{a}}$ Correlation is significant at the 0.01 level, ${ }^{\mathrm{b}}$ Correlation is significant at the 0.05 level

the relationship between antioxidant activity and different phenolic content (Table 4). The total antioxidant capacity and ferric reducing activity power of both fruits showed a very strong correlation $(r>0.8)$ with both phenolic and flavonoid content. The lower values in $\mathrm{IC}_{50}$ of $\mathrm{DPPH}$ had higher antioxidant activity. The scavenging activity $\left(\mathrm{IC}_{50}\right)$ showed a negative correlation with the antioxidant compounds. The scavenging activity of $P$. emblica showed a strong correlation $(\mathrm{r}=0.6-0.79)$ with both phenolic and flavonoid content. This implies the ability of polyphenols to act as antioxidants and neutralize free radicals. Choe et al. (2014) also reported a negative correlation between phenolic content and DPPH radical scavenging activity of ethanol extract of persimmon peel.

\section{Conclusion}

This study indicated that the P. emblica fruit had very high phenolic content and antioxidant activity compared to the E. floribundus fruit. The antioxidative activity of $P$. emblica grown in Bangladesh was very close to the reference antioxidant BHT and ascorbic acid. The antioxidant activity of both fruits showed a clear correlation with the phenolic content proving that the activity is due to the presence of bioactive compounds. Polar solvents especially water and ethanol showed higher efficiency in extracting the phenolic compounds of $P$. emblica, resulting in higher antioxidative activity. However, the effect of single or mixed organic solvent or organic solvent-water mixtures on the extraction of phenolic content and antioxidant activity of $P$. emblica remains to be studied.

\section{Conflict of interest}

The authors have no conflict of interest to declare.

\section{References}

Aiyegoro, O.A. and Okoh, A.I. (2009). Phyotchemical screening and polyphenolic antioxidant activity of aqueous crude leaf extract of Helichrysum pedunculatum. International Journal of Molecular Sciences, 10(11), 4990-5001. https:// doi.org/10.3390/ijms10114990

Aktumsek, A., Zengin, G., Guler, G.O., Cakmak, Y.S. and Duran, A. (2013). Antioxidant potentials and anticholinesterase activities of methanolic and aqueous extracts of three endemic Centaurea L. species. Food and Chemical Toxicology, 55, 290296. https://doi.org/10.1016/j.fct.2013.01.018

Alam, A.K., Hossain, A.S., Khan, M.A., Kabir, S.R., Reza, M.A., Rahman, M.M., Islam, M.S., Rahman, M.A.A., Rashid, M. and Sadik, M.G. (2016). The Antioxidative Fraction of White Mulberry Induces Apoptosis through Regulation of $\mathrm{p} 53$ and NFKB in EAC Cells. PLoS One, 11(12), e0167536. https:// doi.org/10.1371/journal.pone.0167536

Alam, M.N., Bristi, N.J. and Rafiquzzaman, M. (2013). Review on in vivo and in vitro methods evaluation of antioxidant activity. Saudi Pharmaceutical Journal, 21(2), 143-152. https://doi.org/10.1016/ j.jsps.2012.05.002

Belyagoubi, L., Belyagoubi-Benhammou, N., AtikBekkara, F. and Coustard, J.M. (2016). Effects of extraction solvents on phenolic content and antioxidant properties of Pistacia atlantica Desf fruits from Algeria. International Food Research Journal, 23(3), 948-953.

Benzie, I.F.F. and Strain, J.J. (1996). The ferric reducing ability of plasma (FRAP) as a measure of "antioxidant power": the FRAP assay. Analytical Biochemistry, 239(1), 70-76. https:// doi.org/10.1006/abio.1996.0292

Bhebhe, M., Füller, T.N., Chipurura, B. and Muchuweti, M. (2016). Effect of solvent type on total phenolic content and free radical scavenging activity of black tea and herbal infusions. Food analytical methods, 9 (4), 1060-1067. https://doi.org/10.1007/s12161-015$0270-\mathrm{z}$

Chaphalkar, R., Apte, K.G., Talekar, Y., Ozha, S.K. and Nandave, M. (2017). Antioxidants of Phyllanthus emblica L. bark extract provide hepatoprotection against ethanol-induced hepatic damage: A comparison with silymarin. Oxidative Medicine and Cellular Longevity, 2017, 3876040. https:// doi.org/10.1155/2017/3876040

Charoenteeraboon, J., Ngamkitidechakul, C., Soonthornchareonnon, N., Jaijoy, K. and Sireeratawong, S. (2010). Antioxidant activities of 
the standardized water extract from fruit of Phyllanthus emblica Linn. Songklanakarin Journal of Science and Technology, 32(6), 599-604.

Choe, J.H., Kim, H.Y., Kim, Y.J., Yeo, E.J. and Kim, C.J. (2014). Antioxidant activity and phenolic content of persimmon peel extracted with different levels of ethanol. International Journal of Food Properties, 17(8), 1779-1790. https:// doi.org/10.1080/10942912.2012.731460

Deivasigamani, R. and Devi, M.S. (2018). Phytochemical analysis of Elaeocarpus floribundus Blume. World Journal of Pharmacy and Pharmaceutical Sciences, 7(10), 1452-1457.

Do, Q.D., Angkawijaya, A.E., Tran-Nguyen, P.L., Huynh, L.H., Soetaredjo, F.E., Ismadji, S. and Ju, Y.H. (2014). Effect of extraction solvent on total phenol content, total flavonoid content, and antioxidant activity of Limnophila aromatica. Journal of Food and Drug Analysis, 22(3), 296-302. https://doi.org/10.1016/j.jfda.2013.11.001

Ezzati Nazhad Dolatabadi, J., Mokhtarzadeh, A., Ghareghoran, S.M. and Dehghan, G. (2014). Synthesis, characterization and antioxidant property of quercetin- $\mathrm{Tb}(\mathrm{III})$ complex. Advanced Pharmaceutical Bulletin, 4(2), 101-104.

Fitriansyah, S.N., Aulifa, D.L., Febriani, Y. and Sapitri, E. (2018). Correlation of total phenolic, flavonoid and carotenoid content of Phyllanthus emblica extract from Bandung with DPPH scavenging activities. Pharmacognosy Journal, 10(3), 447-452. https://doi.org/10.5530/pj.2018.3.73

Gaire, B.P. and Subedi, L. (2014). Phytochemistry, pharmacology and medicinal properties of Phyllanthus emblica Linn. Chinese Journal of Integrative Medicine. https://doi.org/10.1007/s11655 -014-1984-2

Garsia-Salas, P., Morales-Soto, A., Segura-Carretero, A. and Fernandez-Gutierrez, A. (2010). Phenoliccompound extraction systems for fruit and vegetable systems. Molecules, 15(12), 8813-8826. https:// doi.org/10.3390/molecules 15128813

Gorinstein, S., Poovarodom, S., Leontowicz, M., Viarasilp. S., Haruenkit, R., Ruamsuke, P., Katrich, E. and Tashma, Z. (2010). Antioxidant properties and bioactive constituents of some rare exotic Thai fruits and comparisons with conventional fruits in vitro and in vivo studies. Food Research International, 44(7), 2222-2232. https:// doi.org/10.1016/j.foodres.2010.10.009

Hilton, P.J. and Palmer-Jones, R. (1973). Relationship between the flavanol composition of fresh tea shoots and the theaflavin content of manufactured tea.
Journal of the Science of Food and Agriculture, 24 (7), 813-816. https://doi.org/10.1002/ jsfa.2740240709

Hossain, S.J., Tsujiyama, I., Takasugi, M., Islam, M.A., Biswas, R.S. and Aoshima, S. (2008). Total phenolic content, antioxidative, anti-amylase, anti-glucosidase and antihistamine release activities of Bangladeshi Fruits. Food Science and Technology Research, 14 (3), 261-268. https://doi.org/10.3136/fstr.14.261

Ikram, E.H.K., Eng, K.H., Jalil, A.M.M., Ismail, A., Idris, S., Azlan, A., Nazri, H.S.M., Diton, N.A.M. and Mokhtar, R.A.M. (2009). Antioxidant capacity and total phenolic content of Malaysian underutilized fruits. Journal of Food Composition and Analysis, 22(5), 388-393. https:// doi.org/10.1016/j.jfca.2009.04.001

Khoddami, A., Wilkes, M.A. and Roberts, T.H. (2013). Techniques for analysis of plant phenolic compounds. Molecules, 18(2), 2328-2375. https:// doi.org/10.3390/molecules 18022328

Khopde, S.M., Priyadarsini, K.I., Mohan, H., Gawandi, V.B., Satav, J.G., Yakhmi, J.V., Banavaliker, M.M., Biyani, M.K. and Mittal, J.P. (2001). Characterizing the antioxidant activity of AmLa (Phyllanthus emblica) extract. Current Science, 81(2), 185-190.

Kong, K.W., Mat-Junit, S., Aminudin, N., Ismail, A. and Abdul-Aziz, A. (2012). Antioxidant activities and polyphenolics from the shoots of Barringtonia racemosa (L.) Spreng in a polar to apolar medium system. Food Chemistry, 134(1), 324-332. https:// doi.org/10.1016/j.foodchem.2012.02.150

Krishnaveni, M. and Mirunalini, S. (2010). Therapeutic potential of Phyllanthus emblica (AmLa): the ayurvadic wonder. Journal of Basic and Clinical Physiology and Pharmacology, 21(1), 93-105. https://doi.org/10.1515/JBCPP.2010.21.1.93

Lee, Y.H., Choo, C. and Waisundara, V.Y. (2015). Determination of the total antioxidant capacity and quantification of phenolic compounds of different solvent extracts of black mustard seeds (Brassica nigra). International Journal of Food Properties, 18 (11), 2500-2507. https:// doi.org/10.1080/10942912.2014.986331

Li, Y., Guo, B., Wang, W., Li, L., Cao, L., Yang, C., Liu, J., Liang, Q., Chen, J., Wu, S. and Zhang, L. (2019) Characterization of phenolic compounds from Phyllanthus emblica fruits using HPLC-ESI-TOFMS as affected by an optimized microwave-assisted extraction. International Journal of Food Properties, 22(1), 330-342. https:// doi.org/10.1080/10942912.2019.1583249

Li, Y., Sun, H.Y., Yu, X.Y., Liu, D. and Wan, H.X. 
(2015). Evaluation of cellular antioxidant and antiproliferative activities of five main Phyllanthus Emblica L. cultivars in China. Indian Journal of Pharmaceutical Sciences, 77(3), 274-282. https:// doi.org/10.4103/0250-474X.159608

Liu, X., Zhao, M., Wang, J., Yang, B. and Jiang, Y. (2008). Antioxidant activity of methanolic extract of emblica fruit (Phyllanthus emblica L.) from six regions in China. Journal of Food Composition and Analysis, 21(3), 219-228. https://doi.org/10.1016/ j.jfca.2007.10.001

Lobo, V., Patil, A., Phatak, A. and Chandra, N. (2010). Free radicals, antioxidants and functional foods: Impact on human health. Pharmacognosy Reviews, 4 (8), 118-126. https://doi.org/10.4103/09737847.70902

Mondal, R., Polash, S.A., Saha, T., Islam, Z., Sikder, M.M., Alam, N., Hossain, M.S. and Sarker, S.R. (2017). Investigation of the phytoconstituents and bioactivity of various parts of wild type and cultivated Phyllanthus emblica L. Advances in Bioscience and Biotechnology, 8(7), 211-227. https://doi.org/10.4236/abb.2017.87016

Nunes, P.X., Silva, S.F., da S Almeida, J.R.G., de lima J.T., de Araujo Ribeiro L.A., Quintans Junior L.J. and Filho, J.M.B. (2012). Biological oxidations and antioxidant activity of natural products. In Venketeshwer, R. (Eds.), Phytochem as nutraceuticals - global approaches to their role in nutrition and health. Rijeka, Shanghai: InTech.

Ough, C.S. and Amerine, M.A. (1988). Methods for analysis of musts and wine, p. 400. New York: Wiley.

Oyaizu, M. (1986). Studies on products of browning reaction. Antioxidative activities of products of browning reaction prepared from glucosamine. Japanese Journal of Nutrition and Dietetics, 44(6), 307-315.

https://doi.org/10.5264/ eiyogakuzashi.44.307

Park, J.H., Lee, M. and Park, E. (2014). Antioxidant activity of orange flesh and peel extracted with various solvents. Preventive Nutrition and Food Science, 19(4), 291-298. https://doi.org/10.3746/ pnf.2014.19.4.291

Pisoschi, A.M., Pop, A., Cimpeanu, C. and Predoi, G. (2016). Antioxidant capacity determination in plants and plant-derived products: A review. Oxidative Medicine and Cellular Longevity, 2016, 9130976. https://doi.org/10.1155/2016/9130976

Prieto, P., Pineda, M. and Aguilar, M. (1999). Spectrophotometric quantitation of antioxidant capacity through the formation of a phosphomolybdenum complex: specific application to the determination of vitamin E. Analytical Biochemistry, 269(2), 337-341. https:// doi.org/10.1006/abio.1999.4019

Rahman, M.M., Islam, M.B., Biswas, M. and Alam, A.K. (2015). In vitro antioxidant and free radical scavenging activity of different parts of Tabebuia pallida growing in Bangladesh. BMC Research Notes, 8, 621. https://doi.org/10.1186/s13104-0151618-6

Rahman, M.M., Khan, F.E., Das, R. and Hossain, M.A. (2016). Antioxidant activity and total phenolic content of some indigenous fruits of Bangladesh. International Food Research Journal, 23(6), 23992404.

Shin, T., Fujikawa, K., Moe, A.Z. and Uchiyama, H. (2018). Traditional knowledge of wild edible plants with special emphasis on medicinal uses of Southern Shun State, Myanmar. Journal of Ethnobiology and Ethnomedicine, 14, 48. https://doi.org/10.1186/ s13002-018-0248-1

Sircar, B. and Mandal, S. (2017). Indian olive, Elaeocarpus floribundus fruit: perspective to the antioxidative capacity and antibacterial activity. $E C$ Microbiology, 12(6), 273-282.

Swargiary, A., Nath, P., Basumatary, B. and Brahma, D. (2017). Phytochemical, antioxidant, and trace element analysis of anthelmintic plants of northeast India. International Journal of Pharmacy and Pharmaceutical Sciences, 9(9), 228-232. https:// doi.org/10.22159/ijpps.2017v9i9.20668

Uddin, M.S., Mamun, A.A., Hossain, M.S., Akter, F., Iqbal, M.A. and Asaduzzaman, M. (2016). Exploring the effect of Phyllanthus emblica L. on cognitive performance, brain antioxidant markers and acetylcholinesterase activity in rats: promising natural gift for the mitigation of alzheimer's disease. Annals of Neuroscinces, 223(4), 218-229. https:// doi.org/10.1159/000449482

Utami, R., Khalid, N., Sukari, M.A., Rahmani, M., Abdul, A.B. and Dachriyanus. (2013). Phenolic contents, antioxidant and cytotoxic activities of Elaeocarpus floribundus Blume. Pakistan Journal of Pharmaceutical Sciences, 26(2), 245-50.

Wang, S.Y. and Zheng, W. (2001). Effect of plant growth temperature on antioxidant capacity in strawberry. Journal of Agricultural and Food Chemistry, 49(10), 4977-4982. https:// doi.org/10.1021/jf0106244

Xu, D.P., Li, Y., Meng, X., Zhao, T., Zhao, Y., Zheng, J., Zhang, J.J. and Li, H.B. (2017). Natural antioxidants in foods and Medicinal plants: 
extraction, assessment and resources. International Journal of Molecular Sciences, 18(1), 96. https:// doi.org/10.3390/ijms18010096

Zaman, S. (2016). Exploring the antibacterial and antioxidant activities of Flaeocarpus floribundus leaves. Indo American Journal of Pharmaceutical Sciences, 3(2), 92-97.

Zengin, G., Stefanucci, A., Rodrigues, M.J., Mollica, A., Custodio, L., Aumeeruddy, M.Z. and Mahomoodally M.F. (2018). Scrophularia lucida L. as a valuable source of bioactive compounds for pharmaceutical applications: in vitro antioxidant, anti-inflammatory, enzyme inhibitory properties, in silico studies, and HPLC profiles. Journal of Pharmaceutical and Biomedical Analysis, 162, 225-233. https:// doi.org/10.1016/j.jpba.2018.09.035.

Zhang, Y.J., Gan, R.Y., Li, S., Zhou, Y., Li. A.N., Xu, D.P. and Li, H.B. (2015). Antioxidant phytochemicals for the prevention and treatment of chronic diseases. Molecules, 20(12), 21138-21156. https://doi.org/10.3390/molecules201219753

Zhishen, J., Mengcheng, T. and Jianming, W. (1999). The determination of flavonoid contents in mulberry and their scavenging effects on superoxide radicals. Food Chemistry, 64(4), 555-559. https:// doi.org/10.1016/S0308-8146(98)00102-2

Zietz, M., Weckmuller, A., Schmidt, S., Rohn, S., Schreiner, M., Krumbein, A. and Kroh, L.W. (2010). Genotypic and climatic Influence on the antioxidant activity of flavonoids in Kale (Brassica oleracea var. sabellica). Journal of Agricultural and Food Chemistry, 58(4), 2123-2130. https:// doi.org/10.1021/jf9033909 